\title{
Monitoria e avaliação formativa em nível universitário: desafios e conquistas
}

\author{
Luciane Terra dos Santos Garcia \\ Luiz Gomes da Silva Filho ${ }^{* *}$ \\ Maria Verônica Gomes da Silva ${ }^{* * *}$
}

\section{Resumo}

Este artigo analisa uma experiência de ensino desenvolvida na Universidade Federal do Rio Grande do Norte pela equipe de monitoria da disciplina Organização da Educação Brasileira. Esta disciplina é oferecida aos estudantes dos cursos de licenciatura e as análises das experiências vivenciadas em sala de aula pela equipe mostraram que, em alguns casos, os futuros professores náo valorizavam as disciplinas de formaçáo docente. Assim, a equipe desenvolveu uma pesquisa-ação com o objetivo prático de implementar na turma uma proposta de avaliaçáo formativa, cujo intuito foi o de envolver o educando no processo de ensino-aprendizagem e discutir a importância do trabalho docente. O objetivo teórico consiste em analisar as concepçóes dos licenciandos acerca da sua profissáo e do trabalho pedagógico do qual participaram. Como procedimentos de pesquisa, foram aplicados questionários aos estudantes para conhecer suas concepçóes a respeito da sua futura profissáo, bem como analisados os registros feitos por eles em um caderno referente ao trabalho que estava sendo efetivado em cada aula. A vivência da avaliação formativa colaborou para conscientizar os educandos em relaçáo à corresponsabilidade dos envolvidos no processo de ensinoaprendizagem e, na concepção destes, tornar o ensino superior "mais humanizado". $\mathrm{O}$ atual processo de proletarização docente dificulta a identificação do licenciando com sua profissão, e as representaçôes que constroem a respeito da profissão carregam valores e concepçóes construídas há muito tempo, o que demonstra a importância de discutir o trabalho docente nos cursos especificamente de formação.

Palavras-chave: Monitoria. Avaliação formativa. Pesquisa-ação.

* Doutora em Educação pela Universidade Federal do Rio Grande do Norte (UFRN). Professora do Programa de Pós-Graduação em Educação na UFRN.

** Graduado em Pedagogia pela Universidade Federal do Rio Grande do Norte (UFRN). Mestrando em Educação na Universidade Federal da Paraíba (UFPB).

${ }^{* * *}$ Graduada em Pedagogia pela Universidade Federal do Rio Grande do Norte (UFRN). 


\section{Situando a discussão...}

Este artigo analisará os dados de uma pesquisa-ação resultante do projeto de monitoria intitulado "Açóes integradas e interdisciplinares de monitoria", desenvolvido no período de abril de 2009 a março de 2011, em turmas de licenciatura da Universidade Federal do Rio Grande do Norte (UFRN), campus Natal. A equipe era composta pela professora coordenadora do projeto e por três monitores que se encontravam, semanalmente, para planejar as atividades desenvolvidas, bem como avaliar o processo vivenciado.

Inicialmente, o projeto tinha como objetivo incrementar o desempenho dos alunos por meio da assistência individualizada prestada pelos monitores e de atividades educativas que promovessem diálogo e cooperação entre os envolvidos no processo de ensino-aprendizagem. Posteriormente, o projeto evoluiu para a implementação de práticas de avaliação formativa que pudessem colaborar para a melhoria desse processo e do engajamento dos educandos nas atividades desenvolvidas no componente curricular de Organização da Educação Brasileira.

Esse componente curricular é ministrado em todos os cursos de licenciatura da UFRN, e tem como proposta levar o educando a compreender, historicamente, a organização e o funcionamento da educação básica brasileira, com enfoque nas atuais políticas educacionais e de gestão escolar. A compreensão das relaçôes político-administrativas construídas na escola confere à disciplina fundamental importância para a formação do educador. Apesar disso, as discussóes informais do grupo de monitoria, no primeiro semestre de 2009, sugeriam que alguns licenciandos relutassem em assumir a docência, o que influenciava o seu comprometimento nas disciplinas da área educacional e nas discussóes em sala de aula.

Dessa forma, as reflexóes compartilhadas pelo grupo de monitoria mostraram a necessidade de, no semestre seguinte, conhecer e discutir as concepçôes dos alunos pertinentes à profissão docente, bem como envolvê-los no processo de ensino-aprendizagem. Assim, o grupo de monitoria se propôs a discutir sobre a profissão docente com os licenciandos e instituir práticas de avaliação formativa em uma das turmas em que trabalhava. Com o crescimento qualitativo das reflexôes do grupo, foi desenvolvida uma pesquisa-ação que demandou aprofundamento teórico para que a análise da realidade fosse iluminada pela teoria e apontasse caminhos que colaborassem para a melhoria da qualidade do ensino. Buscou-se, entâo, o aporte da pesquisa-ação para 
subsidiar as reflexôes teórico-metodológicas que seriam desenvolvidas. Para Thiollent (2003, p. 14), a pesquisa-ação consiste em:

[...] um tipo de pesquisa social com base empírica que é concebida e realizada em estreita associação com uma ação ou com uma resolução de um problema coletivo e no qual os pesquisadores e os participantes representativos da situação ou do problema estão envolvidos de modo cooperativo ou participativo.

A pesquisa-ação, portanto, tem como requisito básico a participação dos sujeitos na resoluçáo dos problemas, visto que eles devem se engajar nos processos decisórios e assumir a responsabilidade de concretizar o que definiram coletivamente. No que se refere à participação nos processos decisórios, Pateman (1992), estudiosa da democracia direta, defende que, dentre outros fatores, o envolvimento das pessoas nas deliberaçóes possibilita a responsabilidade individual, social e política com os resultados das açóes que ajudaram a definir e concretizar.

Desse modo, integrar, no projeto de monitoria, uma pesquisa-ação precisaria ser decisão coletiva porque não estava previsto na proposta do projeto original e o empreendimento demandaria maior tempo dos monitores para as reflexôes coletivas e para o planejamento das açôes. Da mesma forma, a turma de alunos que participaria da iniciativa também foi consultada e aceitou tomar parte na experiência assinando termo de concordância. A participação na decisão, por parte dos monitores e estudantes, gerou o compromisso necessário para o desenvolvimento metodológico do trabalho educativo, possibilitando que essa experiência se configurasse como uma pesquisa-ação crítica.

Conforme analisa Franco (2012), a pesquisa-ação crítica se constrói a partir de diferentes vozes que tecem, coletivamente, a metodologia da ação sobre uma situaçáo que vivenciam. Os monitores estavam diretamente envolvidos no planejamento da açáo, em sala de aula, colaboravam com a professora no desenvolvimento das atividades e, ao término, a equipe de monitoria discutia acerca do que foi realizado, além de planejar a continuidade das ações. As vozes dos estudantes da turma eram ouvidas não só em seus posicionamentos nas discussôes em sala de aula, mas também no registro escrito, oportunidade em que avaliavam o trabalho educativo conferindo-lhes poder de influenciar as ações que eram empreendidas. 
A pesquisa-ação não possui passos formais a serem aplicados de forma imediata, mas se constrói na interação dos sujeitos com a realidade que se pretende modificar. Como explica Thiollent (2003, p. 26), a pesquisa-ação constitui-se em um método de pesquisa que "[...] pode ser vista como modo de conceber e organizar uma pesquisa social de finalidade prática e que esteja de acordo com as exigências próprias da ação e da participação dos atores na realidade observada”.

Embora não existam etapas predefinidas na pesquisa-ação, Franco (2012) elenca alguns princípios que norteiam seu desenvolvimento: 1) rejeição das noçóes positivistas de racionalidade, objetividade e verdade; 2) a práxis social como o início e o fim da construção do conhecimento; 3) desenvolvimento do conhecimento por meio de articulaçôes intersubjetivas; 4) realização da pesquisa no ambiente natural dos sujeitos; 5) flexibilidade nos procedimentos e contínuos ajustes metodológicos que possibilitem desenvolver a pesquisa orientada por sínteses provisórias; 6) o método se assemelha a uma espiral cíclica que contempla o exercício do planejamento, ação, reflexão, pesquisa, ressignificação, recomeçando o processo com base no conhecimento adquirido e nas reflexóes.

Considerando a investigação referente a uma ação empreendida a partir desses princípios, essa modalidade de pesquisa possui objetivos imediatos que envolvem a mudança de uma determinada situação, e uma experiência empreendida, documentada e analisada que propicia a construção de conhecimentos que podem ser disseminados. Sendo assim, a pesquisa teve como objetivo prático implementar a avaliação formativa em uma turma de licenciatura da UFRN visando à melhoria do processo educativo e ao engajamento do educando em seu processo de ensino-aprendizagem. Como objetivo de conhecimento, o grupo de monitoria propôs-se analisar as informaçóes obtidas por meio dos instrumentos de avaliaçáo formativa para identificar as concepçóes dos licenciandos sobre o trabalho educativo que estava sendo efetivado e da profissão docente. Os objetivos práticos e de conhecimento desta pesquisa náo se encontram dissociados, mas se complementam de modo que um cria e presta suporte ao alcance do outro.

Com base nesse referencial, o grupo de monitoria dividia o seu tempo de atuação entre a participação nas aulas, que ocorria duas vezes por semana, e os encontros de planejamento, preparação dos materiais didáticos e discussōes das vivências que, geralmente, ocorriam em um desses dias, após as aulas. Nesses encontros, foram planejados os instrumentos de coleta de dados da pesquisa. 
Para a coleta dos dados, foram utilizados questionário e caderno de registro. A análise das informaçóes contidas nesses instrumentos embasou tanto a atuação do grupo durante a intervenção realizada quanto a elaboração deste artigo. O questionário, composto por objetivas e abertas, foi aplicado aos discentes no primeiro dia de aula, com o objetivo de traçar um perfil dos estudantes (idade, curso, rede de ensino em que realizaram a formação anterior, atividades que executavam além da graduação, tempo disponível para estudo, metodologia de estudos predileta) e conhecer por que desejavam ser professores; o que influenciou sua escolha profissional; como definem a educação brasileira e que professor pretendem ser. Dos 60 graduandos regularmente inscritos na turma de Organização da Educaçáo Brasileira (OEB), 44 responderam ao questionário e participaram da investigação.

Este trabalho está organizado em quatro partes: na primeira, discutiremos a importância da monitoria acadêmica na formaçâo de professores; na segunda, será refletido acerca do referencial da avaliação formativa relacionando-o com os modelos normativo e criterial de avaliação; na terceira parte, analisaremos a experiência da avaliaçáo formativa implementada; na última sessão, discutiremos sobre a identidade profissional dos licenciandos envolvidos na pesquisa para, em seguida, traçar algumas as considerações finais.

\section{Monitoria: prática formativa, reflexiva e coletiva}

A monitoria acadêmica constitui-se em uma modalidade de ensinoaprendizagem que atende às necessidades de formação universitária na medida em que envolve o graduando nas atividades de organizaçáo, planejamento e execução do trabalho docente. Dessa forma, consiste em um trabalho pedagógico no qual o professor orienta e é assistido pelo monitor que, por demonstrar ter maior conhecimento em determinada área do conhecimento, o auxilia no processo de ensino-aprendizagem da turma com que estâo trabalhando. Embora a monitoria se desenvolva nos mais variados níveis de escolaridade, tem importância nos cursos de formação de professores por se constituir em mais uma oportunidade de aprendizagem do exercício docente.

$\mathrm{Na}$ UFRN, o Programa de Monitoria é regulamentado pela Resolução $n^{\circ} 013 / 2006$ (UFRN, 2006, p. 1), a qual entende que a melhoria no processo de ensino-aprendizagem nos cursos de graduaçáo acontece em três aspectos: 1) no trabalho do professor; 2) no processo de ensino-aprendizagem do aluno; 3) na formação do monitor. 
No que se refere ao primeiro aspecto, o monitor colabora com o trabalho do professor por se constituir em "[...] apoio pedagógico ao desenvolvimento das atividades do(s) componente(s) curricular(es)" (UFRN, 2006, p. 3). Isso pode acontecer de diversas formas, Masetto (2003) destaca que, na preparação da aula, o monitor pode auxiliar tanto verificando se a linguagem utilizada pelo professor e as estratégias de ensino propostas estão compreensíveis aos discentes quanto na discussão dos encaminhamentos do trabalho docente que serão desenvolvidos com os graduandos.

Assim, tanto na preparação das aulas quanto na sua execução, o trabalho do professor deixa de ser individual, solitário e se torna dialógico, uma vez que ele tem a oportunidade de compartilhar suas impressōes e aprendizagens visando alcançar os objetivos de ensino a que se propóe. O planejamento das situaçóes de aprendizagem e a análise dos resultados das açôes empreendidas conferem maior sistematicidade ao que se quer alcançar, congregando, assim, diversas experiências e conhecimentos em prol de objetivos comuns.

Conforme a teoria da ação comunicativa de Habermas (1990), os sujeitos podem coordenar ações para alcançar objetivos comuns, de modo que os acordos construídos a partir dos conflitos provenientes da diversidade de concepçóes devem ser firmados conscientemente por meio do diálogo. Entendemos que essa diversidade, de fato, contribui para a melhoria do processo de ensino-aprendizagem, pois ao refletirem e dialogarem acerca das situaçóes de aprendizagem vivenciadas, os sujeitos aprendem em conjunto e constroem as bases necessárias às práticas educativas.

Certamente, em determinados aspectos o professor tem mais conhecimento e experiência que o monitor e utiliza-os para justificar suas práticas e posicionamentos. Por outro lado, o monitor também constrói, em diferentes situaçóes de aprendizagem, na universidade ou fora dela, conhecimentos e experiências que permitem colaborar com o trabalho docente. Muitas vezes, por exemplo, os estudantes universitários possuem mais competência para trabalhar com os recursos midiáticos e de informática do que o professor, colaborando assim para o emprego das novas tecnologias na sala de aula.

Conforme Alarcão (2005, p. 29), o que distingue o profissional experiente do novato, "[...] não é tanto a quantidade do saber, mas a sua qualidade, a capacidade de relacionar, seleccionar, ajustar, adaptar ao contexto, prever, pôr em acção a sua flexibilidade cognitiva e fazê-lo com rapidez, espontaneamente e sem esforço". Apesar dessa diferença, a relação dialógica estabelecida entre 
o professor e o monitor acerca da realidade e dos desafios da prática docente, os coloca na condiçấo de colaboradores e de aprendizes que, conforme suas especificidades, colaboram para imprimir mais qualidade ao trabalho educativo.

Por vezes, a proximidade da faixa etária, dialetos utilizados, gostos e própria condição de aprendiz, concorrem para que o monitor medeie a aprendizagem dos demais educandos. Masetto (2003, p. 56) considera que este auxilia na formação do estudante na medida em que, por vezes, auxilia o professor a captar "[...] as dificuldades que os alunos manifestam no curso e na disciplina e ajudá-los a expor esses problemas ao professor [...]". O monitor também favorece a aprendizagem dos alunos ao "[...] incentivar a participação da classe nas atividades propostas [...] e colaborar com a compreensão dos textos" (MASETTO, 2003, p. 56).

A parceria entre professor e monitor na mediação da aprendizagem possibilita o crescimento de ambos. Para o segundo, essa situação é especialmente proveitosa, pois tem a oportunidade de aprofundar seus conhecimentos e vivenciar a prática docente, tendo a orientação e auxílio de um profissional experiente com quem pode discutir a própria atuação. Nesse particular, Pessôa (2007) enfatiza que a monitoria propicia ao graduando desenvolver o interesse pela carreira docente, porque convive com a prática diária do ensino, compartilha vivências pedagógicas que possibilitam a construção da sua identidade pessoal e profissional vinculada à docência. Sendo assim, a monitoria consolida "o aprender e o ensinar, por meio de trocas simultâneas de conhecimentos plurais" (PESSÔA, 2007, p. 9).

É necessário atentar que nem sempre a monitoria se funda em uma ação dialógica que possibilita a aprendizagem e o crescimento dos envolvidos. Em algumas ocasiôes, torna-se um simples auxílio aos educandos na resolução de listas de exercícios. Outras vezes, pode consistir em auxílio técnico para o cumprimento de tarefas burocráticas e também garantir que o que foi planejado isoladamente pelo professor seja posto em prática. Posturas como essas são resquícios de um modelo de educaçáo que hierarquiza e isola os sujeitos responsáveis pelo processo educativo, bem como fragmenta e descontextualiza as práticas profissionais.

Entendemos que a monitoria se constitui em oportunidade de aprendizagem e de crescimento coletivo na medida em que proporciona a vivência da concepção do professor reflexivo. Essa percepção se deriva da concepção de formação profissional proposta por Schön (2000), que 
compreende que o desempenho de um ofício é constituído por um saber-fazer teórico e prático que, por vezes, leva a pessoa a experimentar momentos de incerteza. A orientaçáo de um formador pode auxiliar o iniciante a compreender sua profissão, o que exige reflexão e diálogo com a própria realidade.

Segundo Alarcão (2004, p. 44), a perspectiva do "[...] professor reflexivo, que reflecte em situação e constrói conhecimento a partir do pensamento sobre a sua prática, é perfeitamente transponível para a comunidade educativa que é a escola". Compreender o papel do professor com base nessa perspectiva implica reconhecer que a ação docente está para além do ensino propriamente dito, mas precisa ser interpretada, avaliada, refletida, embasada teoricamente para que esses conhecimentos fundamentem a prática educativa.

Nesse sentido, vivenciar a ação docente conscientiza o monitor da necessidade de buscar respostas para as situaçóes de ensino-aprendizagem que o desafiam, desenvolvendo sua ação profissional em função da construção de um determinado modelo de educação e de sociedade. Para isso, o exercício docente requer conhecimentos e competências específicas, sendo influenciado por representaçôes, imagens e concepçóes de mundo (re)construídos historicamente. Para Ramalho, Nuñes e Gauthier (2004, p. 23, grifos dos autores), a competência profissional do professor se constrói na medida em que assume:

[...] a reflexão, a crítica, a pesquisa como atitudes que possibilitam ao professor participar na construção de sua profissão e no desenvolvimento da inovação educativa, norteia a formaçáo de um profissional não só para compreender e explicar os processos educativos dos quais participa, como também para contribuir na transformação da realidade educacional no âmbito de seus projetos pessoais e coletivos.

Foi nessa perspectiva que evoluíram as discussões do grupo de monitoria responsável pelo projeto "Açóes integradas e interdisciplinares de monitoria". Mediante a prática da avaliação formativa e da coleta de informaçóes, o grupo buscou refletir sobre a ação docente e implementar melhorias nessa ação visando um envolvimento discente mais efetivo com a própria aprendizagem. Dessa forma, passamos a focar na avaliação formativa, discutindo como é possível propiciar a melhoria do processo de ensino-aprendizagem, em relaçáo a outros referenciais avaliativos que coexistem no meio educacional. 


\section{Avaliação normativa, formativa e criterial: implicações educacionais}

A escola constitui-se como uma importante agência socializadora dos indivíduos e difusora de valores, e a avaliação colabora, substancialmente, para isso. A esse respeito, Afonso (2005, p. 27) afirma que "[...] as diferentes modalidades de avaliação terão, elas próprias, impactos muito diferentes na socialização dos indivíduos em escolarização e nem todas serão igualmente funcionais para o mundo do trabalho". Assim, as mudanças socioeconômicas influenciam as formas de avaliação educacional.

O taylorismo/fordismo e as formas de organização do trabalho possibilitaram nas instituiçóes educacionais, principais responsáveis pela formaçáo da força de trabalho, dentre outras funçōes, o desenvolvimento da modalidade normativa de avaliação. Conforme esse parâmetro, a avaliação padronizada possibilitava a quantificação e a comparação dos resultados, constituindo-se em meio privilegiado para fomentar a competição e a hierarquização dos sujeitos, aprovar ou reprovar e, portanto, selecionar os mais aptos.

As mudanças na esfera produtiva e na organização do trabalho, a partir da década de 1970, por conseguinte, demandou a atualização do modelo normativo. Para Afonso (2005), este se relacionava com a ideologia de mercado, de modo que as alteraçôes, nessa esfera, impulsionaram mudanças nas políticas educacionais e, em especial, nas de avaliação, para que os sistemas de ensino desenvolvessem as competências mínimas exigidas pelo mercado. Além disso, o contexto de diminuição do papel do Estado, conforme o ideário neoliberal, tornou a avaliação dos sistemas de educação um importante meio de controle do que é ensinado e de responsabilização dos sujeitos pelos resultados educacionais.

Nessa perspectiva, Dias Sobrinho (2003) destaca que a modalidade de avaliação criterial difundiu-se pelos países desenvolvidos, em especial, nos anos de 1980, e na América Latina, principalmente, na década de 1990. Essa modalidade de avaliaçáo possibilita que o Estado analise em que medida o educando alcançou os objetivos de ensino propostos. Afonso (2005, p. 34) difere a avaliaçáo criterial da normativa afirmando que a primeira "[...] verifica a aprendizagem de cada aluno em relaçáo a objectivos previamente definidos, a avaliação normativa [...] toma como referência, ou compara, as realizaçóes dos sujeitos que pertencem a um mesmo grupo [...]". Esta, portanto, mede 
a aprendizagem e compara os estudantes entre si em um grupo, enquanto a primeira verifica as competências atingidas pelos educandos permitindo maior controle central dos Estados sobre os sistemas de ensino (AFONSO, 2005).

Tanto uma quanto a outra modalidade incidem sobre o produto da aprendizagem para certificá-lo. Para Dias Sobrinho (2003), a avaliação normativa e a criterial, entre outras modalidades, expressam a concepção de ciência que as embasa, o modelo positivista hipotético dedutivo, ao passo que, ao contrário, a avaliaçáo formativa traduz a necessidade de superação desse paradigma para um enfoque qualitativo, global, fenomênico indutivo, orientado ao processo.

Nesse enfoque, a partir da década de 1960, configurou-se a avaliação formativa quando se reconheceu a necessidade de não, apenas, testar a aprendizagem dos educandos, mas também obter dados que colaborassem com a explicação dos resultados educacionais e o acompanhamento das açóes desenvolvidas. Esse tipo de avaliação busca explicar a realidade focando dados subjetivos, qualitativos além de valorizar a participação dos sujeitos. Afonso (2005) esclarece que a avaliação formativa não dispensa a definição de critérios para orientar o processo educativo. Para dar-lhes consecução, utiliza-se de métodos e técnicas diversas de coleta de informaçóes para o acompanhamento do ensino, recorrendo à memória do professor acerca das situaçóes de aprendizagem, observação livre ou sistemática, autoavaliação, entrevistas, trabalhos em grupo, entre outros meios (AFONSO, 2005).

Avaliaçôes de processo, na concepção de Luckesi (2011, p. 172), “[...] além de investigar a qualidade, subsidia, se necessário, a intervençáo para a melhoria dos resultados até o nível do critério preestabelecido". Na sala de aula, portanto, a avaliação formativa acontece durante o processo pedagógico possibilitando que professores e/ou os estudantes tenham o feedback necessário do que foi planejado e está sendo executado, colaborando para o incremento da qualidade do ensino-aprendizagem.

Recentemente, a avaliação formativa vem se difundindo nas escolas brasileiras de educação básica, entretanto, ainda não é muito utilizada no meio universitário, onde muitos profissionais desenvolvem práticas avaliativas fundamentadas no paradigma positivista de educação que se caracteriza pela perspectiva de neutralidade nas práticas de ensino, sendo a prova o principal instrumento de aferição da aprendizagem, capaz de emprestar o rigor que se requer do ensino universitário. Com base nos resultados obtidos, 
selecionam-se os educandos mais aptos, comparam-se os resultados de suas aprendizagens, em função dos quais os alunos são hierarquizados considerando, predominantemente, suas capacidades de memorização.

Dessa forma, a avaliação da aprendizagem quando não legitima a exclusão de muitos do sistema de ensino, pode ainda se constituir em instrumento de competição, capaz de desconsiderar as diferenças individuais, dificultar a aceitação de perspectivas diversas e o desenvolvimento das capacidades de reflexão e de inovação. $\mathrm{Na}$ concepção de De Sordi (2007, p. 235), ao longo do tempo, esse tipo de avaliação no ensino superior tem como consequências:

Marcas visíveis e invisíveis em nossa criatividade; instituição do silêncio e da vergonha; necessidade de aprender a dar respostas e, paralelamente, de desaprender a fazer perguntas; insegurança para experimentar raciocínios mais complexos e por vezes desestabilizadores; aniquilamento de nossa dimensão-águia, capaz de sonhar, olhar para o horizonte e pressagiar mudanças.

Em uma época de intensas mudanças sociais, quando a sociedade exige que as pessoas estejam preparadas para responder aos desafios da incerteza, a buscar conhecimentos e (re)elaborá-los para atender às demandas com as quais se depara, é preciso instituir mudanças nas práticas de ensino-aprendizagem e de avaliação universitários. A educação não tem função em si mesma, mas existe para atender às necessidades sociais que condicionam as práticas e os métodos educativos. Com esse entendimento, cabe salientar que o processo avaliativo pode se constituir em um meio de propiciar o diálogo, a participação, o comprometimento com a mudança, fornecendo, enfim, as informaçóes necessárias ao processo de ensino-aprendizagem.

Distante dessa perspectiva, De Sordi (2007) argumenta que a seleção de conteúdos no ensino universitário tem privilegiado a densidade teórica necessária às demandas do mercado de trabalho. Nesse caso, a competência profissional relaciona-se diretamente com a quantidade de informaçôes recebidas, podendo relegar a segundo plano a reflexão, a dúvida epistemológica, a profundidade das discussões necessárias para que o graduando transforme informaçóes em conhecimentos significativos e duradouros.

Ainda para a autora, desenvolver o trabalho pedagógico orientado pela racionalidade técnica positivista pode tornar a avaliação um meio de reafirmar 
os conteúdos dogmáticos que devem ser memorizados e repetidos pelos estudantes. Assim, o centro desse processo torna-se a obtenção de nota em prejuízo do interesse pelo ato de conhecer. É, portanto, necessário construir uma avaliação universitária cidadâ, incluente e dialógica que possibilite que professores e estudantes se constituam em "[...] partícipes legítimos do processo de ensino-aprendizagem [...] acolhidos em suas carências e estimulados em suas necessidades" (DE SORDI, 2007, p. 239).

Compartilhando com a referida autora que acredita que a avaliação pode se constituir em um importante instrumento de melhoria do processo de ensinoaprendizagem, passamos a analisar uma experiência em que se desenvolve a avaliação formativa em uma turma de nível superior.

\section{Implantação da avaliação formativa: comprometimento dos educandos com o processo de ensino-aprendizagem?}

A vivência da avaliação formativa em uma turma da disciplina de $\mathrm{OEB}$ foi pensada pelo grupo de monitoria com o objetivo de melhorar a qualidade do processo de ensino-aprendizagem e de possibilitar a reflexáo dos educandos em relaçáo ao seu comprometimento com esse processo e com o exercício do magistério, procurando desenvolver práticas que permitissem a construçáo de uma

[...] relação dinâmica de levantamento de informaçôes, de discussão, crítica, reelaboração e construção de novos conhecimentos, em que professor e alunos participam de todo o processo, não [...] [havendo] sentido para uma forma de avaliação que não [...] [fosse] processual e da qual todos os envolvidos não [...] [participassem] ativamente. (KENSKI, 2005, p. 144).

Dessa forma, professores e estudantes são parceiros que compartilham objetivos no processo educativo, de forma que as dificuldades e as aprendizagens dos educandos são consideradas informaçôes que precisam ser estudadas visando à (re)organização desse processo (BOAS, 2006; PERRENOUD, 1999). Com base nas informaçóes coletadas, não só o professor deve avaliar a aprendizagem do educando utilizando diversos instrumentos (provas, observação, trabalhos, etc.), mas também o aluno deve analisar as fragilidades e potencialidades da sua formaçáo refletindo sobre o seu processo de aprendizagem. 
Com relação aos instrumentos de avaliação, Villas Boas (2011) adverte que não existem práticas específicas da avaliação formativa, o que diferencia esta de outras concepções é o modo como as atividades são desenvolvidas e como são utilizadas as informaçôes coletadas. Assim, a prova, geralmente realizada na perspectiva da avaliação somativa com o intento de medir o nível de aprendizagem para aprovar ou reprovar, também pode ser utilizada para subsidiar a aprendizagem, dependendo dos objetivos traçados e do uso que se dá aos dados coletados.

O regimento da UFRN define que, no semestre letivo, cada disciplina seja composta por três unidades avaliativas, sendo facultada ao professor a decisão acerca do número e da forma de avaliação dos educandos. Apesar disso, conforme informação dos alunos no questionário informativo aplicado no primeiro dia de aula, a prova escrita continua sendo predominante tendo em vista a memorização de informaçôes, seleção e hierarquização dos educandos. Essa prova, porém, também pode ser elaborada com fim diverso tornando-se um instrumento de construção de aprendizagem que conjuga aferição de conhecimentos, reflexão sobre os assuntos estudados e oportunidade para que o educando se posicione criticamente. Além disso, combinada a outros instrumentos avaliativos, sua importância pode ser relativizada. Dessa forma, foram desenvolvidos diversos instrumentos que propiciavam tanto a apropriação dos conteúdos quanto a aferição da aprendizagem: mapa conceitual, quadro sinóptico, estudo dirigido, seminário, prova escrita, entrevista com profissionais que atuam em escolas públicas e, por fim, a elaboração de relatório analítico relacionando as informaçóes coletadas nas escolas com o que foi estudado na disciplina.

Para o acompanhamento diário do processo desenvolvido, os estudantes registravam, em um caderno, os objetivos das aulas bem como suas impressóes relativas a esse processo e à atuação dos envolvidos. O conhecimento dos objetivos da aula possibilitava que os graduandos conhecessem o que se esperava deles, os pontos mais significativos de cada conteúdo estudado, para que focalizassem melhor sua aprendizagem. A avaliaçáo de todos os envolvidos no processo de ensino-aprendizagem tornava mais horizontal as relaçóes de poder na sala de aula e aclarava a percepção de que eram corresponsáveis por esse processo. Os dados fornecidos pelos estudantes no caderno passam a compor as análises deste artigo, identificados por nomes fictícios.

Os alunos apreciaram, positivamente, a diversidade de instrumentos de ensino e de avaliação utilizadas na disciplina, pois, dessa forma, atendia-se 
às peculiaridades dos estudantes. Desse modo, Felipe ressaltou a eficácia da elaboração do quadro sinóptico para a compreensão das características da educação brasileira no período colonial. Tiago relatou que se identificou com o estudo dirigido utilizado para discutir as políticas educacionais do período da ditadura militar, expressando-se dessa forma: "Gostei da lista de exercício, orientando como fazer a leitura do texto sobre a ditadura". Já Lucas identificouse com as aulas expositivas dialogadas: "Gostei bastante da aula de hoje, acho as aulas com o Datashow muito mais interessante. Muitas vezes só ouvir não basta é preciso ver a palavra escrita para se ter uma melhor fixação do conteúdo".

As metodologias de ensino eram planejadas pela equipe de monitoria considerando a temática, a quantidade de informaçóes a serem discutidas e o tempo disponível. A atuação dos monitores foi decisiva tanto na elaboração dos instrumentos que exigiam maiores conhecimentos da área de informática quanto na diversificaçáo das atividades propostas. A responsabilidade de dirigir os trabalhos, em sala de aula, era da professora, enquanto os monitores auxiliavam nos estudos e debates envolvendo pequenos grupos e o conjunto dos estudantes. Os monitores também se revezavam na leitura dos cadernos após as aulas, indicando para a professora as críticas e sugestóes mais significativas para a melhoria do trabalho desenvolvido; com base nesse levantamento, eram implementadas as mudanças nas metodologias de trabalho de forma que as atividades mais criticadas não eram repetidas.

Cada educando tinha uma pasta onde se arquivavam os instrumentos didático-avaliativos que eram analisados pela professora, a quem cabia orientar as melhorias, atribuindo determinada pontuação. Ana destacou a importância desse fato: "A avaliação contínua foi muito importante, pois nos ajudou, muitas vezes, a compreender os assuntos que não ficaram muito claros e com essas avaliaçôes nos fazia pensar e refletir mais a fundo".

A despeito da afirmação, para alguns alunos a prova continuava sendo o principal meio de aferição da aprendizagem, como demonstra Lucio: “[...] considero que o conhecimento ainda é o principal fator para ser avaliado e a prova desempenha um importante papel embora não seja o único instrumento". Todas as atividades desenvolvidas tinham como propósito a construçáo do conhecimento, mas parece que esse licenciando considerava que apenas a prova constituía-se em meio legítimo de certificaçáo dos conteúdos apreendidos, visto que tanto na educação básica quanto no ensino superior é o mais utilizado. Por outro lado, outros educandos consideravam um fato positivo na aferiçáo da aprendizagem 
por meio de diversos instrumentos, como demonstra Lucas: "[...] quanto à forma de avaliação, eu achei bastante produtiva, uma vez que é mais justa do que as 'provas' no final das unidades".

Entendemos que a prova escrita não consiste, apenas, em um meio de certificação da aprendizagem, mas também em oportunidade de construção do saber. $\mathrm{Na}$ disciplina de OEB, foram aplicadas duas provas escritas, realizadas em dupla, intercaladas com outros instrumentos de avaliação, conforme já explicitado. Os alunos eram orientados a estudar os textos e, sem consulta ao material, teriam que responder às questôes discutindo entre si. As respostas deveriam demonstrar o conhecimento do conteúdo curricular, relação com a realidade escolar e posicionamento crítico diante das situaçóes abordadas. A prova, de fato, tornou-se uma oportunidade de aprendizagem mediada pela leitura dos textos, pela análise da questão e diálogo entre os educandos.

$\mathrm{O}$ uso de diversos instrumentos de aprendizagem, em especial, o registro das impressôes dos educandos no caderno, demandou um esforço cognitivo maior e mais tempo para conclusão das atividades por parte de todos os envolvidos: da equipe de monitoria no planejamento dos instrumentos e leitura dos cadernos; em especial, da professora a quem competia a correção das atividades; dos estudantes na sua execução e registro das impressóes diárias no caderno. Gabriel, um dos estudantes, salientou que a sistemática adotada foi custosa, mas permitiu um melhor acompanhamento do processo educativo: "[...] a forma como trabalhamos esse semestre, achei ótimo. Um pouco mais trabalhoso, na verdade, mas permitiu que nos analisássemos melhor e facilitou a maneira como o professor vê nosso desenvolvimento". Mediante esse posicionamento, podemos inferir que os registros sobre o processo de ensino-aprendizagem empreendido propiciava não só informações que orientavam a ação docente, mas também a autoanálise por parte dos educandos.

A análise do processo de ensino-aprendizagem e o seu registro não são práticas a que os estudantes de nível superior estejam acostumados, havendo certa resistência, explícita ou não, por parte de alguns. Apesar de os estudantes terem concordado em realizá-los, Lucas assim expressou seu descontentamento com essa atividade: "Embora eu tenha votado pela existência deste caderno, às vezes tenho vontade de queimá-lo até a última página. É muito chato ter que relatar aqui os objetivos das aulas". Esse relato era importante, porque os educandos avaliavam sua aprendizagem em função desses objetivos, mas o acréscimo das atividades nem sempre era bem aceito. Nesse caso, o diálogo entre professor e 
aluno, na sala de aula ou por meio do caderno, foi relevante para o entendimento do que se propunha.

A princípio, a participação da turma nas discussôes em sala de aula foi um desafio, visto que muitos se mantinham em silêncio. Nas autoavaliaçóes, alguns alunos mostravam que não haviam realizado previamente as leituras necessárias; esse fato poderia denotar descompromisso do estudante com a disciplina, falta de tempo considerando a quantidade de atividades que desempenhavam ou ainda que muitos não haviam desenvolvido uma cultura de leitura cotidiana. Assim, as atividades foram planejadas para garantir um período de tempo para leitura parcial do texto, o que não dispensava o estudo prévio, cuja falta restringia a qualidade das discussóes. Apesar disso, muitos consideraram esse escasso tempo em sala necessário para o desenvolvimento das atividades propostas e que, juntamente com a explicação da professora e a própria participação passiva nas discussões, tinham alcançado os objetivos propostos.

Em relação à dinâmica desenvolvida, o ponto mais criticado pelos alunos quanto à utilização dos cadernos foi a necessidade de mais tempo para discussão. Enquanto alguns consideravam que as falas dos colegas deveriam ser limitadas prevalecendo a voz da professora, outros consideravam que a participação estava diretamente relacionada com o interesse despertado pelos assuntos em discussão. A esse respeito, Fátima afirma:

[...] as aulas têm sido muito proveitosas. Discussöes calorosas em disciplina de educação nunca foram muito frequentes. Considerar isso élevar em consideração que as manifestaçôes dos alunos se dão pelo interesse despertado através da didática adotada pelo professor. Vejo isso como um ponto 'positivissimo' [...].

Apesar de alguns alunos terem destacado a dificuldade que sentiam na feitura dos registros e a falta de tempo para leitura dos textos, consideravam-se contemplados em suas expectativas e mais confiantes por saberem que o processo de ensino-aprendizagem era de responsabilidade compartilhada. Esse sentimento contribuiu para que alguns estudantes tivessem maior comprometimento com a disciplina, pois percebiam que suas preocupaçôes com a aprendizagem tinham o respaldo da equipe de monitoria. Fátima assim expressou o conforto que isso lhe causava: "Muito agradável a importância que a professora tem dado às nossas inquietaçôes". $\mathrm{Na}$ avaliação final da disciplina, a mesma aluna assim se expressou: 
Pelo respeito demonstrado pela professora e monitores, venho por meio deste caderninho 'táo falado' e inquietante agradecer pelo contato com um ensino superior humanizado. Muitas foram as liçóes, grandes os aprendizados. Espero levar para a vida, praticando no meu dia a dia, a preocupação individualizada pelas consideraçóes dos meus alunos.

Segundo Fátima, a avaliação da aprendizagem, promovida pela equipe de monitoria na disciplina de $\mathrm{OEB}$, diferenciou-se de outras vivenciadas no meio universitário, por conferir ao estudante centralidade no processo de ensinoaprendizagem, direito de expressar suas fragilidades além de o professor assumir com eles a responsabilidade de superaçáo das dificuldades. Considerando que o professor começa a formar o seu perfil profissional, com base nas experiências desenvolvidas desde aluno, é provável que a situação vivenciada influencie as práticas da entấo futura professora.

Visto que a responsabilidade com a aprendizagem era compartilhada por todos, a autoavaliação tornou-se o alicerce do trabalho empreendido, porque se parte do pressuposto de que a professora, os monitores e os estudantes são capazes de analisar sua atuação de forma crítica e reflexiva. Conforme argumenta Vilas Boas (2006, p. 186), "[...] quem realiza o trabalho é quem o conhece melhor. Estudantes familiarizados com a autoavaliação geralmente avaliam-se adequadamente e são mais capazes de encontrar deficiências em suas produções do que outras pessoas".

A princípio, os estudantes registravam no caderno, apenas, suas impressóes atinentes ao trabalho do professor e das metodologias de ensino adotadas, assinalando os pontos que deveriam ser retomados e o que pensavam com relação ao assunto discutido em sala de aula. Essas informações foram primordiais para os planejamentos das aulas subsequentes pela equipe de monitoria e para que determinados assuntos fossem retomados visando garantir a aprendizagem. No entanto, raras eram as referências dos educandos acerca do próprio desempenho, demonstrando que não eram habituados a fazer uma avaliação.

Foi necessário que o professor mostrasse à turma que a responsabilidade pela aprendizagem não era exclusiva do professor, mas dependia principalmente do empenho deles próprios. Por isso, eles deveriam se avaliar também e verificar se estavam cumprindo os requisitos necessários à construção da própria aprendizagem. Nessa perspectiva, Lucas assim se pronunciou: " $A$ aula de hoje 
poderia ter sido mais produtiva se eu tivesse conseguido tirar xerox do texto que foi usado nessa aula". A esse respeito, Érica exprimiu-se: "A leitura do texto não foi feita ainda por mim, por isso senti um pouco de dificuldade, mas a discussão e as colocaçôes feitas foram de suma importância para absorção do conteúdo". Em muitos casos, a consciência da necessidade de leitura dos textos não implicou a leitura efetiva, mas mostrou o reconhecimento de que parte da responsabilidade do processo de ensino-aprendizagem é do aluno.

No caso investigado, a avaliação contínua foi considerada positiva pelos alunos e equipe de monitoria, mostrando a importância de compartilhar responsabilidades em sala de aula. Isso pode ter consequências que não se restringem à disciplina em apreço, mas influenciar, inclusive, o futuro exercício profissional dos licenciandos. Certamente, a demonstração de responsabilidade por parte da equipe de monitoria na condução dos trabalhos educativos e $\mathrm{o}$ atendimento das necessidades pessoais de aprendizagem dos licenciandos levaram a um maior comprometimento da maioria da turma com a própria aprendizagem. Outros ressaltaram o número de atividades que precisavam desenvolver e buscavam desempenhá-las em quantidade e qualidade suficiente para a obtenção da nota para aprovação na disciplina, o que não inviabilizou a experiência no seu objetivo de melhorar o comprometimento do educando com sua própria aprendizagem.

\section{Ser professor: concepções e identidades em formação}

$\mathrm{Na}$ turma da disciplina de OEB, oferecida pelo Departamento de Fundamentos e Políticas Educacionais, do Centro de Educaçáo, da UFRN, onde se desenvolveu a pesquisa, havia graduandos de diversas áreas e cursos de licenciatura: História, Artes, Ciências Sociais, Letras, Ciências Biológicas, Física, Matemática, entre outros. Alguns deles resistiam à ideia de que se preparavam para o exercício da profissáo docente, outros compreendiam que os saberes da sua área específica de conhecimento eram suficientes para esse exercício, o que resultava em pequeno envolvimento com as disciplinas pedagógicas.

A equipe de monitoria decidiu, entâo, discutir com os futuros professores sobre suas concepçóes acerca da profissão docente, para, então, deixar clara a importância das disciplinas pedagógicas na sua formação e engajá-los na melhoria do aproveitamento em sala de aula. Assim, no primeiro dia de aula, foi aplicado um questionário com o objetivo de conhecer o perfil da turma com 
quem se trabalhava e compreender o que pensavam acerca da profissão escolhida. Os dados coletados foram organizados na forma de gráficos e/ou tabelas pelos monitores e apresentados e discutidos com a turma na aula seguinte. Esses dados são, agora, revisitados para compor um dos muitos retratos existentes sobre a profissão docente, desta vez pintado por aqueles que se preparam para exercer essa profissão.

A escolha de uma profissão não acontece ao acaso, em especial a de professor que, conforme Kenski (2005), envolve um conjunto de reflexóes e de ponderaçóes até que se concretize. $\mathrm{O}$ ingresso em um curso preparatório para o magistério implica grande responsabilidade visto que a educação escolar tem a finalidade de cooperar na formação sociocultural, política e profissional do ser humano e os professores são os profissionais que acompanham esse processo com maior proximidade. Apesar de tamanha responsabilidade, a história daqueles que optam por assumi-la no Brasil tem sido marcada, recentemente, pela desvalorizaçáo social traduzida em baixos salários e difíceis condiçóes de trabalho, implicando, às vezes, o receio dos jovens em escolher essa profissão.

Essa realidade encontra-se intimamente ligada às transformaçóes pelas quais o trabalho docente tem passado na sociedade capitalista, uma vez que as mudanças socioeconômicas, políticas e culturais, iniciadas na década de 1970, não só influenciaram as reformas educacionais em diferentes países como também repercutiram diretamente no cotidiano da escola. Analisando o trabalho docente sob esse prisma, Duarte (2001) constata que as mudanças sociais afetaram as relaçóes familiares e têm levado o docente a desempenhar diferentes papéis (psicólogo, assistente social, enfermeiro, entre outros). Para a autora, isso tem gerado indecisóes, apatia, desespero e o adoecimento dos professores e, por vezes, a desistência do exercício profissional.

Duarte (2011) analisou um conjunto de artigos publicados na América Latina sobre o trabalho docente e afirma que a extensão das demandas sociais que chegam à escola tem gerado conflitos profissionais nos docentes e a ruptura do sentido pedagógico da função. Além disso, deixa claro que as reformas educacionais desenvolvidas na regiáo, inspiradas em uma lógica mercantil, vêm atribuindo novas funções aos docentes, causando uma intensificação do seu trabalho e a redução da sua atuação política. Por fim, a autora analisa que o exercício da docência ainda é afetado por difíceis condiçóes materiais, pelos baixos salários da categoria, pelas novas formas flexibilizadas de contratação de serviços, pelas longas jornadas de trabalho, além de outros aspectos. 
Tudo isso tem dificultado que os futuros professores construam a sua própria imagem profissional, que se refere "[...] ao significado pessoal e social que a profissão tem para a pessoa. Se o professor perde o significado do trabalho tanto para si próprio como para a sociedade, ele perde a identidade com a sua profissão" (LIBÂNEO, 2001, p. 77). Assim, apesar de a discussão acerca da identidade docente não constar no ementário da disciplina, a equipe de monitoria considerou importante efetivá-la em sala de aula.

Nesse caso, buscamos conhecer se os alunos da turma desejavam, de fato, ser professores, uma vez que, supostamente, essa escolha já havia sido realizada no momento da opção pelo curso. As respostas foram organizadas na tabela seguinte:

Tabela 1 - Deseja ser professor?

\begin{tabular}{|c|c|c|c|c|}
\hline Sim & Não & Não informou & Indeciso & Total \\
\hline 34 & 5 & 3 & 2 & 44 \\
\hline
\end{tabular}

Fonte: Dados coletados pelos pesquisadores por meio de questionário.

Do montante inquirido, podemos considerar que $25 \%$ dos que frequentavam a disciplina estavam indecisos ou não queriam assumir a profissão docente. Interrogados sobre os fatores que os tinham levado a optar pelo magistério, assim, se posicionaram:

Tabela 2 - Razóes da opçáo dos licenciandos pelo magistério

\begin{tabular}{|l|c|}
\hline \multicolumn{1}{|c|}{ Respostas } & Total de alunos \\
\hline Identificação profissional & 20 \\
\hline Amplo mercado de trabalho & 6 \\
\hline Ter diploma universitário & 5 \\
\hline Influência de bons exemplos profissionais ou familiar & 5 \\
\hline Deseja realizar prática diferente de seus professores & 4 \\
\hline Compreender relação entre educaçáo e sociedade & 2 \\
\hline Não responderam & 2 \\
\hline Total & 44 \\
\hline
\end{tabular}

Fonte: Dados coletados pelos pesquisadores por meio de questionário.

Constatamos, pois, que a maioria escolheu a profissão por identificação e/ou influência de bons ou maus profissionais que desejam igualar-se ou diferenciar-se, respectivamente. Já muitos outros escolheram a profissão em 
meio a conflitos que, em parte, decorrem das imagens desenvolvidas acerca da profissão docente, bem como das experiências pessoais vivenciadas ora como educandos ora como professores. Assim, as boas e más situaçôes vividas, o conhecimento das condiçôes de trabalho do professor, as críticas dirigidas aos profissionais com quem conviveram, os bons profissionais que marcaram a vida dessas pessoas, a pouca atratividade com relação aos salários da categoria; a existência de instituições educacionais diferentes para classes sociais diferentes, a expressiva quantidade de vagas em concursos públicos, o descompromisso do Estado na manutençáo do sistema educacional de qualidade social para todos são alguns dos fatores que permeiam a escolha da profissão docente. Existem pontos positivos e negativos que influenciam cada caso particular.

Os conflitos aumentaram quando foi solicitado aos licenciandos que definissem a educação básica brasileira, seu futuro campo profissional, utilizando uma palavra, cujos resultados foram organizados nas categorias constantes da tabela 3 .

Tabela 3 - Como os futuros professores definem a educaçáo brasileira?

\begin{tabular}{|l|l|}
\hline \multicolumn{1}{|c|}{ Categorias } & Porcentagem \\
\hline De forma negativa & $61 \%$ \\
\hline Ressaltaram necessidade de superação & $18 \%$ \\
\hline Não responderam & $13 \%$ \\
\hline Ressaltaram sua importância & $6 \%$ \\
\hline
\end{tabular}

Fonte: Dados coletados pelos pesquisadores por meio de questionário.

Como demonstra a tabela 3, 61\% dos graduandos utilizaram expressões negativas, tais como: desvalorizada, carente, desorganizada, fracassada, insatisfatória. Outros 18\% enfatizaram o desafio de superar a situação atual da educação brasileira descrevendo-a como esperança, desejo, compromisso. 13\% dos estudantes preferiram não responder à questão. Por fim, $6 \%$ destacaram a sua importância, pois a viram como orientaçâo para os educandos, oportunidade de desenvolvimento pessoal, mas ressaltaram a necessidade de o professor se atualizar para acompanhar o desenvolvimento social.

Apesar da maioria dos licenciandos criticar, negativamente, as condiçóes em que o exercício docente se desenvolve e a prática de algumas pessoas que têm atuado no magistério, outros reconheceram a importância sociocultural, política e econômica da profissão. Por meio da educação escolar, acontece, em 
maior ou em menor grau, a socialização de valores, a difusão de conhecimentos, a construção da crítica, o estímulo à criatividade, a preparação para o trabalho, em suma, a formação humana. A docência, pois, precisa ter sua importância reconhecida nessa formação, e, para tanto, possui conhecimentos próprios e traz as marcas de um ofício desenvolvido ao longo de geraçóes (ARROYO, 2002). Nesse sentido, Libâneo (2001) enfatiza uma série de estudos recentes que revelam que os docentes possuem um conjunto de conhecimentos teóricos e práticos, além de qualidades, capacidades, habilidades e atitudes que, relacionados, possibilitam o exercício adequado da profissão.

Vivemos, no entanto, em um momento histórico em que as transformaçóes socioeconômicas, culturais e políticas se aceleram, a sociedade clama por mudanças da escola e critica os professores que possuem dificuldade em se adaptar a esse momento. No cenário das críticas, por um lado, as elites exigem que a escola modernize suas práticas educativas, sem descuidar do culto a antigos valores que mantêm a estabilidade da sociedade de classes. Por outro, as classes populares criticam a escola pública por não se reconhecerem nas práticas nela desenvolvidas.

Em um contexto de sucateamento das escolas públicas, proletarização docente e desrespeito com a educação da classe trabalhadora, os professores, por vezes, são os únicos apontados como responsáveis pelos insatisfatórios resultados educacionais do país. Nessas condiçôes, integrantes da elite e da classe média, geralmente com uma melhor formação educacional, buscam se distanciar da profissão docente, enquanto que, em uma época de escassez de emprego em especial na esfera pública, contraditoriamente, as classes populares ainda encontram na docência o atrativo da conquista do emprego público.

Apesar de estigmatizada, a docência ainda é capaz de despertar o desejo de realização profissional de muitos, como é o caso daqueles estudantes identificados com essa profissão e desejosos para se engajar no movimento para sua transformação. Isso acontece provavelmente porque, conforme Arroyo (2002), a profissáo de professor consiste em um modo de ser que invade os diferentes tempos históricos identificando-se com a vida pessoal, que carrega incômodos, mas também heranças sociais que interconecta fatores afetivos, religiosos, culturais, políticos, éticos e técnicos.

Essas heranças sociais certamente influenciaram a concepção que os licenciandos da turma de OEB possuem acerca da profissão e do tipo de professor que eles pensavam em ser. Indagados sobre as características 
profissionais que pretendiam desenvolver no exercício da profissão, eles responderam de forma bastante variada. Agruparam-se os dados em três grandes categorias englobando: 1) as atitudes desejadas em um professor; 2) os conhecimentos que deveriam ter; 3 ) os valores que devem demonstrar. Sendo assim, 46\% dos licenciandos destacaram que o professor deve apresentar atitudes como compromisso, dedicação, paciência, capacidade para motivar os alunos, compreensão, dinamismo e seriedade; $23 \%$ compreendem que a docência requer competências e conhecimentos que permitam atuar com clareza e objetividade, utilizar métodos diversificados, pesquisar sobre diversos assuntos; e $8 \%$ dos estudantes destacaram a formação de valores que propiciem o respeito mútuo e a formação de cidadãos, sendo que uma pessoa enfatizou o desejo de exercer a docência em escola destinada às classes populares. Por fim, $4 \%$ afirmaram que não sabiam e $19 \%$ não responderam.

As falas dos estudantes investigados traduzem um conjunto de imagens construídas socialmente concernentes à profissão docente. Barroso (2003) afirma que a evolução dessa profissão é permeada por um caleidoscópio de imagens assumidas em diferentes épocas históricas que se desenvolveram em funçáo das expectativas de representantes políticos, de trabalhos desenvolvidos na área educacional ou ainda de estratégias criadas pelos docentes visando acomodar interesses diante de constrangimentos vividos no exercício da profissão.

Barroso (2003) demonstra, ainda, que o professor é reconhecido socialmente por imagens como a de missionário, proletário, profissional e militante. A imagem do professor missionário está relacionada ao serviço inestimável que presta à sociedade e ao seu exemplo de idoneidade moral, altruísmo, dedicação, paciência, civismo e perseverança. No entanto, a realidade em que o docente desempenha suas funçóes o aproxima da imagem de funcionário do ensino que executa os programas educacionais submetido a uma condição de proletarização profissional. Os baixos salários, as várias jornadas de trabalho, a falta de investimento na formação teórico-metodológica deixam sem as condiçôes necessárias para levar o aluno a aprender. Ainda para o autor, diversos fatores contribuíram para que se desenvolvesse a imagem do professor como profissional, que valoriza a competência técnica do professor, sem considerar o envolvimento político no trato com a profissão. Desse modo, em contraposição a essa imagem, se construiu a postura do militante preocupado com a transformação social, mas que descuida, muitas vezes, da competência de especialista. 
Nas falas dos estudantes que responderam ao questionário predominam as figuras do missionário e a do profissional. Acerca desse fato, Cunha (2005) analisa que o professor é uma construção social de forma que as expectativas da sociedade influenciam, em grande medida, os seus comportamentos. Visto que as ideias das classes dominantes predominam na sociedade nas diferentes épocas, elas acabam por ter ascendência sobre as concepções acerca do que é ser professor. Assim, ainda conforme a autora, o bom professor, geralmente, é retratado pelos alunos como aquele que domina o conteúdo, apresenta bem a matéria, possui um bom relacionamento com os educandos, mas, dificilmente, eles fazem alusão ao seu posicionamento político.

A discussão em sala de aula referente às concepçôes profissionais dos alunos de $\mathrm{OEB}$, a avidez por compreender as raízes históricas dos problemas educacionais brasileiros, as discussóes acerca da especificidade dos saberes docente e da importância do professor na formação de todos os demais profissionais, vêm possibilitando o repensar do papel político-pedagógico dos que exercem esse ofício. Experiências desse tipo levaram os licenciandos a confirmar sua opção pela docência ou a rever a rejeição inicial, conforme expressam os estudantes Júlio e Lucas, respectivamente:

Ao término do periodo, tenho a certeza, estou convicto da minha escolha em relação à docência, graças a tantos professores que me ajudaram a perceber isto, e neste caso a professora [...] por sua delicadeza e dedicação em facilitar e provocar a busca pelo conhecimento. Adorei a forma como foram realizadas as avaliaçóes, extremamente proveitosas.

Aprendi muita coisa e meu senso crítico sobre a educação evolui consideravelmente. Esse último trabalho, as idas à escola, a entrevista com a direção e a coordenação pedagógica somados ao meu trabalho no PIBID me fizeram ver a escola e sua mecânica de um outro modo que eu passei a reavaliar a possibilidade de ser professor.

Embora o objetivo da pesquisa-ação desenvolvida não fosse o de convencer os licenciandos a assumir a docência, as discussóes acerca do que é ser professor, do seu papel político-pedagógico, aliado ao retorno à realidade da educação básica para entrevistar seus profissionais, colaborou para uma 
mudança na perspectiva da valorização da profissão. Isso implicou reconhecer a sua importância, os conhecimentos e as competências específicas que esse exercício requer, além da complexidade do que é a formação de seres humanos.

\section{Considerações finais}

O trabalho pedagógico da equipe de monitoria teve uma mudança qualitativa com a decisão de implementar práticas de avaliação formativa e pesquisar acerca delas. Com isso, a equipe se fortaleceu como sujeito coletivo que aprende, ensina e reflete sobre o que faz. Para que esse projeto fosse pensado e concretizado, a equipe de monitoria vivenciou um contínuo processo de planejamento, execução e avaliação das açóes que contribuiu para (res)significação da própria prática educativa e potencialização de um exercício docente coletivo, que propiciou aprendizagens a todos os envolvidos.

Ressaltamos a participaçáo dos monitores nas discussóes e planejamento das atividades, apresentando ideias originais e pontos de vista diferenciados que qualificavam os debates. A contribuiçáo deles foi especialmente sentida na elaboração dos gráficos e formulários utilizados durante o curso, além de pesquisas de referências em meio digital que, na época, demandavam conhecimentos náo dominados pela professora. Por outro lado, os monitores se beneficiaram com a disponibilidade e experiência profissional da professora no momento dos planejamentos, na orientaçáo da postura que deveriam assumir em sala de aula, como, por exemplo, auxiliar a aprendizagem discente, na utilizaçáo dos materiais para estudo. A contribuiçáo mais significativa da experiência realizada para a equipe de monitoria foi a certeza de que a docência e a pesquisa devem estar atreladas em prol da melhoria da qualidade do trabalho desempenhado.

O acompanhamento do processo educativo por meio da avaliaçáo formativa demandou a utilizaçáo de diversos instrumentos de ensinoaprendizagem que tornaram a avaliação contínua. No acompanhamento do processo educativo, destacamos a utilizaçáo do caderno de registro que permitiu a coleta de informaçôes referentes às aprendizagens e às dificuldades dos graduandos, a crítica à metodologia de ensino empregada, à ação da professora e dos monitores, além da autoavaliaçâo do educando. Isso tornou a ação educativa mais consciente sobre o desenvolvimento da aprendizagem do educando em relação aos objetivos que se esperava alcançar na disciplina. 
Não obstante a pouca experiência dos alunos com a prática da autoavaliação, as ponderações foram determinantes para a consciência da responsabilidade compartilhada por todos na construção da aprendizagem. Mas nem sempre isso, juntamente com o diálogo desenvolvido em sala de aula, foi suficiente para que o educando procedesse à leitura prévia dos textos que seriam discutidos, que seria condição para se imprimir maior qualidade ao diálogo e à aprendizagem do que se estudava.

A vivência da avaliação formativa na licenciatura proporcionou não apenas o acompanhamento processual da aprendizagem e a melhoria do processo pedagógico, mas, sobretudo, considerada pelos alunos uma forma de humanização do ensino superior. Isso provavelmente, porque, nesse nível, em nome da imparcialidade nas relações, da racionalidade técnica e da eficiência profissional, as pessoas estão esquecendo a importância da formação humana em sua complexidade e múltiplas necessidades. O "caderninho tâo falado" conferiu mais do que voz aos que, muitas vezes, têm sido mantidos calados, respeito às diferenças individuais, mas também despertou o sentido da igualdade entre os que buscam o saber, o sentido da crítica e da autocrítica sobre o que se realiza.

De modo geral, as falas dos educandos da disciplina de OEB revelaram que as suas representaçóes acerca da profissão docente carregam valores e concepçóes construídas desde longas datas, que influenciam a forma como assumem a profissão docente e pretendem exercê-la. A imagem do professor missionário que desempenha o seu ministério com empenho religioso e independente de altas remunerações, o recente processo de proletarização e de desvalorização da categoria fazem com que muitos licenciandos relutem em assumi-la, evidenciando os conflitos vivenciados.

A experiência de avaliação da aprendizagem vivenciada na disciplina de OEB consistiu em uma experiência formativa para os futuros professores. Os licenciandos iniciaram a aprendizagem da profissão ainda enquanto estudantes, criticando e refletindo sobre os modelos dos professores com quem conviveram, cujas práticas são criticadas, julgadas, copiadas ou rechaçadas conforme parâmetros próprios. Assim, essa experiência soma-se a outras já vividas pelos estudantes na constituição do repertório e pode ser melhor aproveitada na vivência da prática docente. 


\section{REFERÊNCIAS}

AFONSO, Almerindo Janela. Sociologia da avaliaçẫo: problemas de delimitação de um campo teórico-conceptual e de investigação. In: AFONSO, Almerindo Janela. Avaliação educacional: regulação e emancipação para uma sociologia das políticas avaliativas contemporâneas. 3. ed. São Paulo: Cortez, 2005. p. 27-34.

ALARCÃO, Isabel de. Professores reflexivos em uma escola reflexiva. 3. ed. São Paulo: Cortez, 2004. (Coleção questóes de nossa época).

ALARCÃO, Isabel de. Reflexão crítica sobre o pensamento de D. Schön e os programas de formação de professores. In: ALARCÃO, Isabel de (Org.). Formação reflexiva de professores: estratégias de supervisão. Porto: Porto Editora, 2005. p. 29-44.

ARROYO, Miguel G. Ofício de mestre: imagens e auto-imagens. Petrópolis, RJ: Vozes, 2000.

BARROSO, João. A formação de professores e a mudança organizacional das escolas. In: FERREIRA, Naura Syria Carapeto (Org.). Formação continuada e gestão da educação. São Paulo: Cortez, 2003.

BOAS, Benigna Maria de Freitas Villas. O projeto político-pedagógico e a avaliação. In: VEIGA, Ilma Passos Alencastro; RESENDE, Lúcia Maria Gonçalves de (Org.). Escola: espaço do projeto político-pedagógico. 10. ed. Campinas, SP: Papirus, 2006. p. 179-200.

BOAS, Benigna Maria de Freitas Villas. Compreendendo a avaliação formativa. In: BOAS, Benigna Maria de Freitas Villas (Org.). Avaliação formativa: práticas inovadoras. Campinas, SP: Papirus, 2011.

CUNHA, Maria Isabel da. O bom professor e sua prática. 17. ed. Campinas, SP: Papirus, 2005.

DE SORDI, Mara Regina Lemes de. Avaliação da aprendizagem universitária em tempos de mudança: inovação ao alcance do educador comprometido. In: VEIGA, Ilma Castro Alencastro; CASTANHO, Maria Eugênia L. M. (Org.). Pedagogia universitária: a aula em foco. Campinas, SP: Papirus, 2007. p. 135-239. 
DIAS SOBRINHO, José. Avaliação: políticas educacionais e reformas da educação superior. São Paulo: Cortez, 2003.

DUARTE, Adriana. Políticas educacionais e o trabalho docente na atualidade: tendências e contradições. In: DUARTE, Adriana; OLIVEIRA, Dalila Andrade. Políticas públicas e educação. Belo Horizonte, MG: Fino Traço, 2011. p. 161-182.

FRANCO, Maria Amélia Santoro. Pedagogia da pesquisa-ação. Educação e Pesquisa, São Paulo, v. 31, n. 3, p. 483-502, set./dez. 2005. Disponível em: <http://www.scielo.br/pdf/ep/v31n3/a11v31n3.pdf>. Acesso em: 10 jan. 2012.

HABERMAS, Jürgen. Introdução: o materialismo histórico e o desenvolvimento de estruturas normativas. In: HABERMAS, Jürgen. Para a reconstrução do materialismo histórico. 2. ed. Tradução de Carlos Nelson Coutinho. São Paulo: Brasiliense, 1990. p. 12-45

KENSKI, Vani Moreira. Repensando a avaliação da aprendizagem. In: VEIGA, Ilma Veiga Passos Alencastro (Org.). 22. ed. Repensando a didática. Campinas, SP: Papirus, 2005.

LIBÂNEO, José Carlos. Organização e gestão da escola: teoria e prática. Goiânia: Alternativa, 2001.

LUCKESI, Cipriano Carlos. Avaliação da aprendizagem: componente do ato pedagógico. São Paulo: Cortez, 2011.

MASETTO, Marcos T. Competência pedagógica do professor universitário. São Paulo: Summus, 2003.

PATEMAN, Carole. Participaçâo e teoria democrática. Tradução de Luiz Paulo Rouanet. Rio de Janeiro: Paz e Terra, 1992.

PERRENOUD, Philippe. A parcela de avaliação formativa em toda avaliação contínua. In: PERRENOUD, Philippe. Avaliação: da excelência à regulação da aprendizagem - entre duas lógicas. Tradução de Patrícia Chittoni Ramos. Porto Alegre: Artmed, 1999. 
PESSÔA, Jacira Magalhães. Programa de monitoria como prática de formação do professor-contador: percepçóes e identidade. In: SIMPÓSIO BRASILEIRO DE POLÍTICA E ADMINISTRAÇÃO DA EDUCAÇÃO, 23. 2007, Porto Alegre. Anais eletrônicos... Porto Alegre: ANPAE, 2007. Disponível em: <http://www.anpae.org.br/congressos_antigos/ simposio2007/188.pdf>. Acesso em: 10 jan. 2012.

RAMALHO, Betânia Leite; NUNEEZ, Isauro Béltran; GAUTHIER, Clermont. Formar o professor profissionalizar o ensino: perspectivas e desafios. 2. ed. Porto Alegre: Sulinas, 2004.

SCHÖN, Donald. Ensinando o talento artístico através da reflexão-na-ação. In: SCHÖN, Donald. Educando o profissional reflexivo: um novo designe para o ensino e a aprendizagem. Tradução de Roberto Cataldo Costa. Porto Alegre: Artmed, 2000.

THIOLLENT, Michel. Metodologia da Pesquisa-ação. São Paulo: Cortez, 2003.

UFRN. Universidade Federal do Rio Grande do Norte. Resolução no 013/2006, CONSEPE, de 14 de março de 2006. Estabelece normas para o Programa de Monitoria da Universidade Federal do Rio Grande do Norte. Natal, 2006. 


\section{Le monitorat et l'évaluation formative dans le niveau universitaire: défis et réalisations}

\section{Résumé}

Cet article analyse une expérience de l'enseignement developpé à l'Université Fédérale du Rio Grande do Norte, par l'équipe de la discipline Organisation de l'Éducation Brésilienne. Cette discipline est offerte aux étudiants des cours de formations de professeurs et les analyses des expériences vécus en classe par l'équipe ont montré que, en certains cas, les futures professeurs ne valorisaient pas les disciplines de formation des enseignants. Ainsi l'équipe a développé une recherche action avec l'objectif pratique d'implémenter dans le groupe une proposition d'évaluation formative, dont le but a été d'engager l'apprenant dans le processus d'enseignanceapprentissage et discuter l'importance du travail des enseignants. L'objectif théorique, c'est l'analyse des conceptions des enseignants en formation sur leur profession et sur le travail pédagogique réalisé. Comme méthode de recherche on a utilisé des questionaires adressés aux apprenants pour connaître leurs conceptions sur sa future profession. On a aussi analysé les enregistrements faits par eux sur un cahier à propos du travail qui se developpait à chaque classe. L'expérience de l'évaluation formative a colaboré pour la conscientisation des

\section{Monitoring and formative evaluation at university level: challenges and achievements}

\section{Abstract}

This article analyzes a teaching experience developed by the monitoring team of the Organization of Brazilian Education discipline at Federal University of Rio Grande do Norte. This discipline is offered to students who are doing bachelor degree courses. The analyses carried out in classroom by the monitoring team have shown that, in some cases, the future teachers do not value the disciplines devoted to teacher training. Thus, the team developed an action-research in the class with the practical objective of implementing a proposal of formative evaluation whose major aim was to involve the student in the teachinglearning process and to discuss the importance of the teacher work. The experience of formative assessment has contributed to make students aware of the shared responsibility of all people involved in the teaching-learning process, and, in their conception, to turn the learning-teaching process "more humanized". The current process of teacher proletarization makes difficult the identification of the graduated teachers with their profession, and the representations that they construct in relation to the profession carry values and conceptions constructed a long time ago. This demonstrates the 
apprenants sur la corresponsabilité des engagés au processus d'enseignementapprentissage et, à leur conception, faire une enseignance supérieure "plus humanisé . Le processus en cours de proletarisation de l'enseignant dificulte l'indentification $\mathrm{du}$ professeur en formation avec sa profession et les représentations qu'ils construisent sur elle portent des valeurs et des conceptions construites il y a longtemps, ce qui montre l'importance de discuter le travail de l'enseignant dans les cours de formation en particulier.

Mots-clés: Monitorat. Évaluation formative. Recherche action

\section{Luciane Terra dos Santos Garcia}

E-mail: ltsgarcia@gmail.com

Luiz Gomes da Silva Filho

E-mail: luizgomes8@gmail.com

Maria Verônica Gomes da Silva

E-mail: marivero84@gmail.com importance of discussing the work of the teacher in specific formation courses.

Keywords: Monitoring. Formative assessment. Action research.

Recebido em: 14/10/2012

Versão final recebida em: 23/7/2013

Aprovado em: 28/7/2013 